\title{
Phosphorylation regulates association of the transcription factor Pho4 with its import receptor Psel/Kap121
}

\author{
Arie Kaffiman, ${ }^{1}$ Nicole Miller Rank, ${ }^{1}$ and Erin K. O'Shea ${ }^{2}$ \\ Department of Biochemistry and Biophysics, University of California, San Francisco, California 94143-0448 USA
}

\begin{abstract}
The transcription factor Pho4 is phosphorylated and localized predominantly to the cytoplasm when budding yeast are grown in phosphate-rich medium and is unphosphorylated and localized to the nucleus upon phosphate starvation. We have investigated the requirements for nuclear import of Pho4 and find that Pho4 enters the nucleus via a nonclassical import pathway that utilizes the importin $\beta$ family member Psel/Kap121. Psel binds directly to Pho4 and is required for its import in vivo. We have defined the nuclear localization signal on Pho4 and demonstrate that it is required for Psel binding in vitro and is sufficient for PSE1-dependent import in vivo. Phosphorylation of Pho4 inhibits its interaction with Psel, providing a mechanism by which phosphorylation may regulate import of Pho4 in vivo.
\end{abstract}

[Key Words: N uclear import; Pse1; Kap121; Pho4; phosphorylation]

Received June 18, 1998; revised version accepted July 10, 1998.

One way in which cells respond to extracellular signals is by modulating gene expression. This response requires the transfer of information from the plasma membrane, through the cytoplasm, and into the nucleus. Protein kinase cascades are commonly used to transduce extracellular signals, and they typically culminate in the phosphorylation of transcription factors. Phosphorylation of both transcription factors and kinases has been shown to result in regulation of their nuclear localization, suggesting that control of the subcellular localization of these proteins is important for the response to extracellular signals (for review, see Jans and Hubner 1996; Gaits et al. 1998; Khokhlatchev et al. 1998; Toone et al. 1998).

The subcellular localization of proteins can be controlled by regulating import into the nucleus and/or by regulating export from the nucleus. N uclear import and export occur through the nuclear pore complex, a large macromolecular assembly of proteins embedded in the nuclear envel ope. Transport is signal mediated, requires energy and physiological temperature, and is bidirectional. Targeting signals are recognized by sol uble transport receptors, which then translocate with their cargo into or out of the nucl eus (for review, see Nigg 1997).

The first targeting signal to be described was the SV40 large $T$ antigen nuclear localization signal (NLS), consisting of a cluster of basic amino acids (Kal deron et al. 1984). The import receptor that recognizes the classical

\footnotetext{
${ }^{1}$ These authors contributed equally to this work.

${ }^{2}$ Corresponding author.

E-MAIL oshea@biochem.ucsf.edu; FAX (415) 502-4315.
}

NLS is a heterodimer consisting of importin $\alpha$ and importin $\beta$. Importin $\alpha$ binds di rectly to the N LS (Gorlich et al. 1994; Weis et al. 1995), and importin $\beta$ binds to importin $\alpha$, the GTPase Ran, and the nucl ear pore complex (Gorlich et al. 1995a; Moroianu et al. 1995; Rexach and Blobel 1995). A complex consisting of the N LS, importin $\alpha$, and importin $\beta$ assembles in the cytoplasm, docks at the nuclear pore, transl ocates across the pore, and then is disassembled in the nucleus (Newmeyer and Forbes 1988; Richardson et al. 1988; Gorlich et al. 1995b; Imamoto et al. 1995; Rexach and Blobel 1995; Moroianu et al. 1996).

Additional signals have been defined that target proteins from the nucleus to the cytoplasm (for review, see N akiel ny and Dreyfuss 1997). The nuclear export signal (NES) contained in the HIV Rev protein and PKI, an inhibitor of CAMP dependent protein kinase A, is a small sequence rich in leucine residues (Wen et al. 1995). The leucine-rich NES is bound by the export receptor Crml/ Xpol and Ran-GTP in the nucleus. This complex translocates across the nuclear pore, and is disassembled in the cytoplasm (Fornerod et al. 1997; Fukuda et al. 1997; Kudo et al. 1997; N eville et al. 1997; Ossareh-N azari et al. 1997; Stade et al. 1997).

A recent advance in the nuclear transport field is the discovery of multiple import and export pathways that utilize different transport receptors (for review, see $\mathrm{Na}$ kielny and Dreyfuss 1997; Weis 1998). This has led to the identification of a family of transport receptors related in sequence to importin $\beta$, with the amino terminus being most conserved in $\mathrm{a} \sim 150$ amino acid region required for binding to the small GTPase Ran (Gorlich et al. 1997). 
Searches of the yeast genome database reveal ed 13 proteins with significant homology to importin $\beta$ (Gorlich et al. 1997). Several of these importin $\beta$ family members have now been shown to be import or export receptors, and it has been postulated that the remainder are transport receptors defining novel import or export pathways. $M$ any studies are focused on determining the functions of the different importin $\beta$ family members.

Ran plays an essential role in nuclear import and export; it is thought that the nucleotide state of Ran is used to impart directionality to transport processes (Gorlich et al. 1996; Izaurral de et al. 1997). The regulators of Ran are compartmentalized within the cell; RanGAP, the Ran GTPase activating protein, is local ized to the cytoplasm and RCC 1, the guanine nucleotide exchange factor for Ran, is exclusively nuclear (Ohtsubo et al. 1989). The localization of RanGAP and RCC 1 predicts that the GTP-bound form of Ran will predominate in the nucleus. The steep gradient of Ran-GTP between the nucleus and the cytoplasm controls assembly and disassembly of transport complexes. Ran-GTP binding by importin $\beta$ family members facilitates release of import receptors from their cargo in the nucleus (Rexach and Blobel 1995; Schlenstedt et al. 1997). Ran-GTP binding by importin $\beta$ family members involved in export is required for the formation of export complexes consisting of the export receptor, cargo, and Ran-GTP (Fornerod et al. 1997; Kutay et al. 1997, 1998). Thus, transport receptors utilize the Ran-GTP gradient as a marker for nuclear and cytoplasmic compartments.

Eukaryotic cells have taken advantage of the barrier between the cytoplasm and nucleus as a way to restrict access to the nucleus and to control the activity of regulatory proteins. Although there are many examples of regulated localization, for most systems it is not clear if import and/or export is regulated or how this regulation is achieved. Until recently, it was assumed that import into the nucleus was the step subject to regulation. The identification of multiple export pathways suggests that the localization of some proteins might be regulated at the level of export. A goal of the field is to understand the regulation of nuclear import and export. One major challenge is to understand how signal transduction pathways influence the import and export of regulatory proteins to control their subcellular localization in response to extracellular signals.

We are studying the regulation of Pho4, a yeast transcription factor whose localization is regulated by phosphorylation in response to changes in the extracellular concentration of inorganic phosphate $\left(\mathrm{O}^{\prime} \mathrm{N}\right.$ eill et al. 1996). Pho4 is required for phosphate starvation-specific gene expression (for review, see Oshima 1997). When yeast are grown in phosphate-rich medium, Pho4 is phosphorylated by the Pho80-Pho85 cyclin-CDK complex (Kaffman et al. 1994) and is local ized predominantly to the cytoplasm (O'N eill et al. 1996), resulting in transcriptional repression of phosphate starvation-specific gene expression. Upon phosphate starvation, the CDK inhibitor Pho81 inhibits Pho80-Pho85 (Schnei der et al. 1994), leading to accumulation of unphosphorylated
Pho4 in the nucleus and transcription of phosphateresponsi ve genes (O'N eill et al. 1996).

We are interested in understanding how phosphorylation of Pho4 regulates its subcellular local ization in response to changes in extracellular inorganic phosphate. We find that Pho4 is imported into the nucleus via a nonclassical import pathway utilizing the importin $\beta$ family member Psel/Kap121. Pho4 is the first protein found to be imported exclusively by Psel. We identify the Pho4 N LS and demonstrate that this region is both necessary for Psel binding in vitro and sufficient for PSEl-dependent nuclear import in vivo. Additionally, we demonstrate that the interaction between Pho4 and Psel is inhibited by phosphorylation, suggesting that import of Pho4 in vivo is regulated by phosphorylation. Our studies provide insight into the mechanism by which phosphorylation of Pho4 regulates its import, and serve as a paradigm for understanding other examples of regulated nuclear localization.

\section{Results}

Nuclear import of Pho4 is defective in a psel-1 strain

Localization of Pho4 is regulated by phosphorylation in response to changes in the extracel lular concentration of inorganic phosphate. A mechanistic understanding of the control of Pho4 localization by phosphorylation requires identification of the transport receptors that carry Pho4 into and out of the nucleus. To identify transport receptors required for import of $\mathrm{Pho4}$, we examined the localization of Pho4 green fluorescent protein (GFP) in different yeast strains containing mutations in the importin $\beta$ family members. In a wild-type strain, Pho4GFP is predominantly cytoplasmic when cells are grown in phosphate-rich medium and is concentrated in the nucleus when yeast are starved for phosphate (Fig. 1). In a yeast strain harboring a temperature-sensitive mutation in the essential importin $\beta$ family member PSE1 (Seedorf and Silver 1997), also referred to as KAP121 (Rout et al. 1997), we find that Pho4-GFP does not accumulate in the nucleus upon phosphate starvation (Fig.

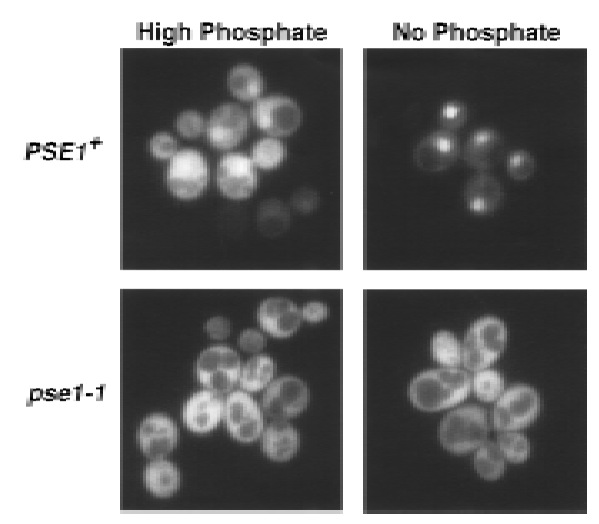

Figure 1. Pho4-GFP does not accumulate in the nucleus in psel-1 yeast. Pho4-GFP localization was monitored in PSE $1^{+}$ (PSY 580) or psel-1 yeast grown at $25^{\circ} \mathrm{C}$ in either high- or nophosphate medium. 
1). The defect in Pho4 localization is observed even at the permissive temperature in a psel-1 strain. Other strains with mutations in the importin $\beta$ family members KAP104, LOS1, MTR10, SXM1, XPO 1, and CSE1 (Hopper et al. 1980; Xiao et al. 1993; Kadowaki et al. 1994; Aitchison et al. 1996; Seedorf and Silver 1997; Stade et al . 1997) do not show a defect in localization of Pho4-GFP upon phosphate starvation (data not shown).

The requirement of Psel for nuclear accumulation of Pho4 could reflect a role for Psel in transducing the phosphate starvation signal, or a role for Psel in import of Pho4. To determine if Psel is required for Pho4 import, we examined the localization of Pho4 ${ }^{\mathrm{SA}}$, a Pho4 mutant contai ning five serine-to-al anine substitutions at the sites of phosphorylation by Pho80-Pho85 (O'N eill et al. 1996). Pho4 ${ }^{\mathrm{SA}}$ is localized to the nucleus of a wildtype strain even when phosphate is abundant ( $\mathrm{O}^{\prime} \mathrm{N}$ eill et al. 1996). Thus, Pho4 ${ }^{\mathrm{SA}}$ can be used to assess the requirements for Pho4 import that are independent of the function of the phosphate signal transduction pathway. In contrast to what is observed in wild-type yeast, $\mathrm{Pho}^{\mathrm{SA}}$ GFP localizes predominantly to the cytoplasm in a psel-1 mutant strain (Fig. 2), indicating that Psel is required for the import of Pho4 into the nucleus.

Previous studies have suggested that Psel and a closely related importin $\beta$ family member, Kap123, might have overlapping functions (Rout et al. 1997; Schlenstedt et al. 1997; Seedorf and Silver 1997). We wished to test if Kap123 also plays a role in the import of Pho4 by examining Pho4 ${ }^{\mathrm{SA}}$-GFP localization in a kap123 $\Delta$ strain. We find no defect in the import of Pho4 ${ }^{\text {SA }}$-GFP in a kap123 4 strain (Fig. 2), indicating that this importin $\beta$ family member is not required for the import of Pho4.

If the mislocalization of Pho4 in a psel-1 mutant strain reflects a defect in a specific import pathway rather than a defect that renders Pho4 incompetent for import, it should be possible to target Pho4 to the

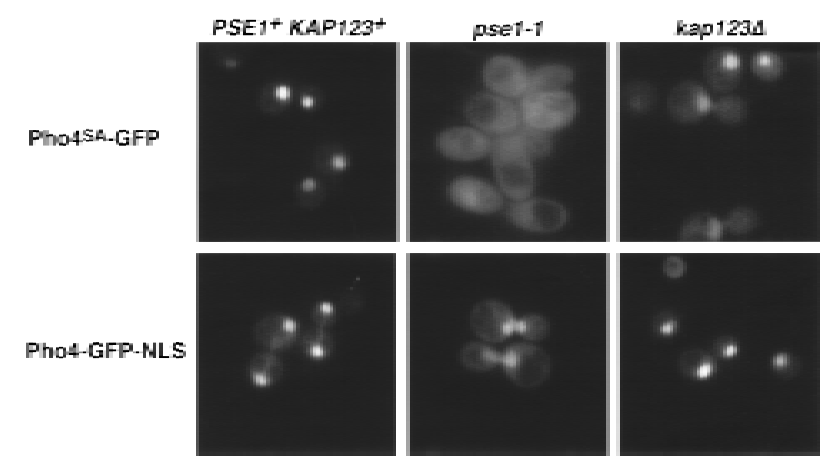

Figure 2. Nuclear import of $\mathrm{Pho}^{\mathrm{SA}}-\mathrm{GFP}$ is defective in psel-1 yeast. The steady-state localization of $\mathrm{Pho}^{\mathrm{SA}}$-GFP and Pho4GFP-N LS was monitored in PSE1 ${ }^{+} \mathrm{KAP} 123^{+}$(PSY 580), pse1-1, or

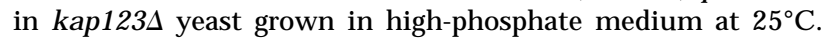
$\mathrm{Pho}^{\mathrm{SA}}$-GFP is a mutant derivative of Pho4 that contains serine-to-alanine substitutions at all of the sites of phosphorylation by Pho80-Pho85 (O'N eill et al. 1996). Pho4-GFP N LS contains the SV40 NLS fused to the carboxyl terminus of Pho4GFP. nucleus in a pse1-1 mutant strain by use of an al ternate import pathway. Strains with mutations in either PSE1 or KAP123 are capable of importing a reporter protein targeted to the nucleus with an NLS derived from the SV 40 large T antigen (Seedorf and Silver 1997). We fused the SV 40 large $T$ antigen N LS to Pho4-GFP (Pho4-GFP$\mathrm{NLS}$ ) and examined its local ization in a wild-type strain,

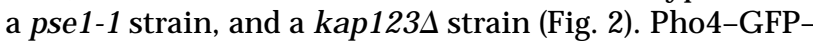
N LS is local ized to the nucleus in each of these strains, suggesting that the defect in Pho4 import in a psel-1 mutant is the result of a defect in a specific import pathway. Taken together, these data suggest that Psel is the import receptor for Pho4.

\section{Identification of the Pho4 NLS}

To identify regions of Pho4 required for its import, we constructed several Pho4 del etion mutants as fusion proteins with GFP and analyzed their local ization in a strain lacking PHO80. Pho4 cannot be phosphorylated in a pho80 $\Delta$ strain, leading to its constitutive nucl ear localization (Kaffman et al. 1994; O'N eill et al. 1996) and thereby simplifying analysis of the steady-state localization of the fusion proteins. The N LS of many transcriptional regulators resides within the DNA-binding domain (Williams et al. 1997; Latimer et al. 1998). Mutational analysis of Pho4 demonstrates that the Pho4 DN A binding domain (Fig. 3A) is neither necessary nor sufficient for nuclear localization in a pho80s strain (Pho4 ${ }_{2-247^{-}}$ GFP, Pho4 $248-312-\mathrm{GFP}_{3}$, Fig. 3B). The smallest domain necessary for Pho4 import lies within amino acids 157164 (Pho4 $_{\Delta 157-164}-$ GFP, Fig. 3B); however, this small domain is not sufficient for nuclear import (Pho4 ${ }_{156-171^{-}}$ $\mathrm{GFP}_{3}$, Fig. 3B). Amino acids 140-166 of Pho4 define the smallest domain of $\mathrm{Pho} 4$ that is both necessary (Pho4 ${ }_{\Delta 141-165}$ GFP, Fig. 3B) and sufficient (Pho4 ${ }_{140-166^{-}}$ $\mathrm{GFP}_{3}$, Fig. 3B,C) for nuclear import. These data demonstrate that Pho4 amino acids 140-166 function as an N LS in vivo (Fig. 3B,C). The Pho4 ${ }_{140-166}-\mathrm{GFP}_{3}$ fusion protein is not imported into the nucleus in a psel-1 mutant, indicating that this fusion protein is targeted to the nucleus via the PSE1-dependent import pathway (Fig. 3C). It is interesting to note that this domain of Pho4 contains a single site for phosphorylation by Pho80Pho85 (Fig. 3D). Pho4 $140-166-\mathrm{GFP}_{3}$ is localized to the nucleus in both high- and low-phosphate media (data not shown), presumably because the peptide N LS cannot be phosphorylated by the Pho80-Pho85 kinase. These studies demonstrate that Pho4 contains a single N LS, which is targeted to the nucleus in a PSE1-dependent manner.

Pho4 binds to Psel directly

If Psel is the import receptor for Pho4, we expect Psel to bind to Pho4. To test for interaction between Pho4 and Psel, we purified a fusion protein from Escherichia coli consisting of Pho4 joined to two Protein A z domains ( $z z$ ) derived from Protein A (Pho4 ${ }^{\mathrm{WT}}-\mathrm{zz}$ ). Pho4 ${ }^{\mathrm{WT}}-\mathrm{zz}$ was immobilized on IgG Sepharose and incubated with extract derived from yeast expressing Psel-GFP. The resin was washed, bound proteins were eluted from Pho4 ${ }^{\mathrm{WT}}-\mathrm{zz}$, 
A

B

Figure 3. Pho4 amino acids 140-166 are necessary and sufficient for nuclear localization. (A) Structure and function of Pho4. A domain important for Pho4 transactivation is contained within Pho4 amino acids 1-109 (hatched box) (Ogawa and Oshima 1990). The Pho4 DNA-binding domain has been localized to amino acids 248-312 (shaded box) (Ogawa and Oshima 1990). The five sites on Pho4 phosphorylated by the kinase Pho80Pho85 are at amino acids 100, 114, 128, 152, and 223 (O'N eill et al. 1996) and are shown with an asterisk $(*)$. The Pho4 N LS lies within amino acids 140-166 (solid box). (B) Localization of Pho4-GFP derivatives. Pho4-GFP derivatives expressed in pho4 $\Delta$ pho80 $\Delta$ yeast were grown at $30^{\circ} \mathrm{C}$ in high-phosphate medium. Pho4 del etion mutants smaller than 27 $\mathrm{kD}$ were fused to three copies of GFP $\left(\mathrm{GFP}_{3}\right)$, and those larger were fused to a single GFP. Localization of the Pho4-GFP derivatives is indicated [(N) nuclear; (C) cytoplasmic]. (C) Pho4 amino acids $140-166$ are sufficient to target $\mathrm{GFP}_{3}$ to the nucleus in a PSE1-dependent manner. Localization of $\mathrm{Pho}_{140-166^{-}}$ $\mathrm{GFP}_{3}$ was monitored in $\mathrm{PSEl}^{+}$(pho4 $\Delta$ pho80 $\Delta$ ) and in psel-1 strains grown at $25^{\circ} \mathrm{C}$ in high-phosphate medium. (D) The Pho4 N LS resides within amino acids $140-166$. The fourth phosphorylation site at Pho4 serine152 is boxed.

\section{D}

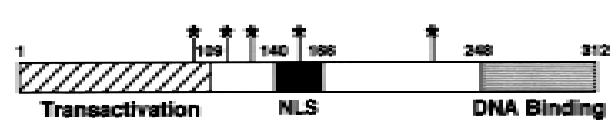

Phot-GFP Derivetive

PhotgrF

Pho4,24, GiF

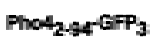

Phot $_{24}$ SII $^{-\mathrm{GPP}_{3}}$

Photase-1ae GirP

Phot $4172-1$ 196-GFP

Phot $4141-165$ GifP

Phot 457 -16r-GFP

Photar-17T-GFP

Phot $16-16 \mathrm{GFP}_{3}$

Phot $_{140-17} \mathrm{GPP}_{3}$

Pho4 $_{156-17}$ GrPP $_{3}$

$\mathrm{FhO}_{140-166}-\mathrm{GFP}_{3}$

C ${\text { PhO4 } 140-166-\mathrm{GFP}_{3}}$

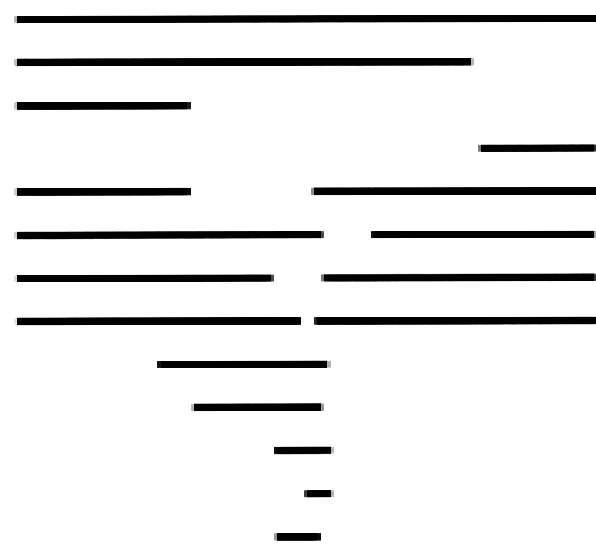

Localiration

N

N

c

c

c

N

c

c

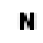

N

M

c

M
Pho4 NLS
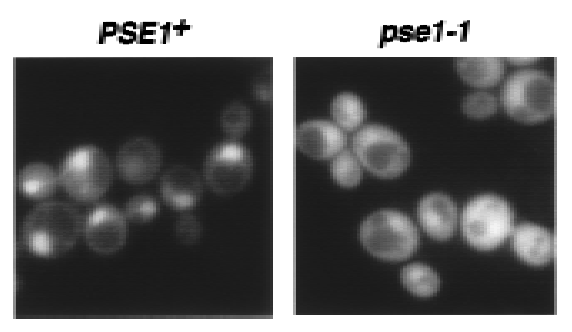

separated by SDS-PAGE, and analyzed by immunoblotting with anti-GFP antibodies. We find that Pho4 ${ }^{\mathrm{WT}}-\mathrm{Zz}$ binds Psel-GFP (Fig. 4B). As a control for the functional relevance of the Pho4-Psel interaction, we examined interaction of Psel with Pho4 ${ }_{\Delta 157-164}-\mathrm{ZZ}$, a Pho4 mutant that cannot be targeted to the nucleus (Figs. 3B and 4A). $\mathrm{N}$ o detectable interaction is observed between $\mathrm{Pho}_{\triangle 157-}$ 164-ZZ and Psel-GFP (Fig. 4B, lane 3). However, both Pho4 $_{\triangle 157-164^{-Z Z} \text { and Pho4 }}{ }^{\mathrm{WT}}$-zz interact to the same extent with the transcription factor Pho2, known to bind Pho4 (Magbanua et al. 1997), suggesting that both proteins are properly folded (data not shown). These data indicate that Psel and Pho4 interact and suggest that the interaction is functionally relevant for import of Pho4.

To examine the specificity of the interaction between Pho4 and Psel, we tested for interaction between Pho4 and the closely related importin $\beta$ family members Sxm 1 and Kap123 (Gorlich et al. 1997; Seedorf and Si lver 1997). In yeast extract, neither Kap123-GFP nor Sxm1-GFP binds immobilized Pho4 ${ }^{\mathrm{WT}}$-zz (Fig. 4C). These results are consistent with the in vivo localization data (Fig. 2) and suggest that the interaction between Pho4 and Psel is specific for this importin $\beta$ family member.
N ext, we wished to determine if the interaction be tween Psel and Pho4 was direct, or mediated by another protein. To test for a direct interaction between Pho4 and Psel, we incubated Pho4 ${ }^{\mathrm{WT}}-\mathrm{zz}$ with Psel-6H is, both purified from $\mathrm{E}$. coli, in the presence of either yeast extract or bovine serum albumin. We find that Pho4 ${ }^{\mathrm{WT}}-\mathrm{zz}$ binds directly to Psel-6His and that this interaction is not potentiated by proteins in the yeast extract, indicating that Psel directly recognizes Pho4 (Fig. 5).

\section{The Psel-Pho4 complex is disassembled by Ran-GTP}

Studies of other import receptor-cargo interactions suggest that they form stable complexes in the cytoplasm, which are then dissociated in the nucleus by binding to Ran-GTP (Rexach and Blobel 1995; Moroianu et al. 1996; Schlenstedt et al . 1997). We wished to determine if the Pho4-Psel complex could be dissociated by incubation with the yeast Ran homolog, Gspl. Psel-6His was prebound to Pho4 ${ }^{\mathrm{WT}}-\mathrm{zz}$ and the Psel-Pho4 ${ }^{\mathrm{WT}}-\mathrm{zz}$ complex was incubated with either Gsp1-GTP, Gspl-GDP, or a buffer control. Psel dissociates from Pho4 when incubated with Gsp1-GTP, but not when incubated with 
A
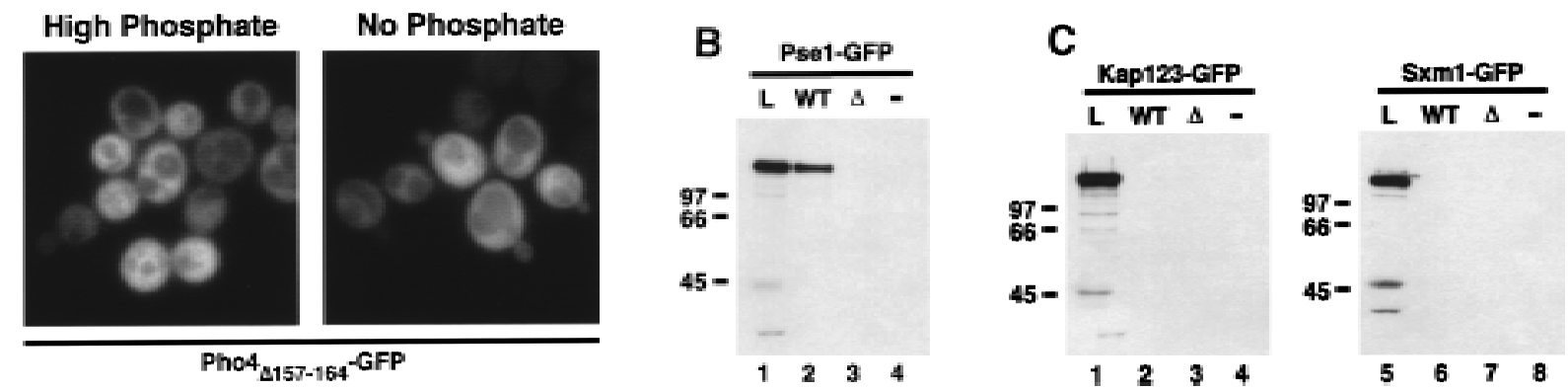

Figure 4. Pho4 binds to Psel. (A) A mino acids 157-164 are required for nuclear local ization of Pho4 in vivo. Pho4 lacking amino acids 157-164 fused to GFP (Pho4 ${ }_{\Delta 157-164}$-GFP) was expressed in pho4 $\Delta$ yeast grown in high- or no-phosphate medium at $30^{\circ} \mathrm{C}$. (B) Pho4 associates with Psel, but a mutant Pho4 lacking residues required for nuclear local ization does not. Wild-type Pho4 (Pho4 ${ }^{\mathrm{WT}}$-zz) and Pho4 lacking amino acids 157-164 (Pho4 ${ }_{\Delta 157-164-Z z)}$ were expressed as zz fusion proteins in E. coli. zz-containing proteins were purified with IgG-Sepharose beads and incubated with yeast extract containing Psel-GFP. The resin was washed extensively and proteins bound to Pho4-zz were el uted with $1 \mathrm{M} \mathrm{M} \mathrm{gCl}_{2}$. Eluted proteins were precipitated, separated on 7.8\% SDS-PAGE, transferred to a PVDF membrane, and visualized by immunoblotting with anti-GFP monoclonal antibodies. (Lane 1) Three percent of the

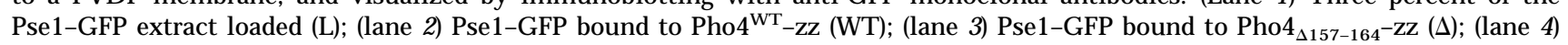
Psel-GFP bound to IgG-Sepharose beads (-). Half of the $1 \mathrm{M} \mathrm{M} \mathrm{gCl} 2$ eluate was loaded onto the gel. (C) Pho4 associates with Psel but

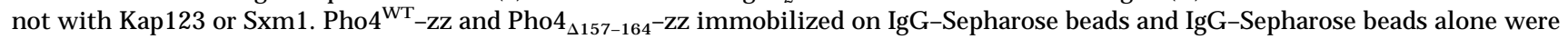
incubated with yeast extract expressing either Psel-GFP, Kap123-GFP, or Sxm1-GFP. The resin was washed extensively, and proteins bound to Pho4-zz were eluted with $1 \mathrm{M} \mathrm{M} \mathrm{MCl}_{2}$. Eluted proteins were precipitated, separated on 7.8\% SDS-polyacrylamide gels, transferred to PVDF membrane, and visual ized by immunoblotting with anti-GFP monoclonal antibodies. (B,C) (Lanes 1,5) About 3\% of the importin-GFP loaded; (lanes 2,6) importin-GFP bound to Pho4 ${ }^{\mathrm{WT}}$-zz; (lanes 3,7) importin-GFP bound to Pho4 ${ }_{\Delta 157-164}-\mathrm{Zz}$; (lanes 4,8) importin-GFP bound to the IgG-Sepharose control. Half of the $1 \mathrm{M} \mathrm{M} \mathrm{gCl} 2$ eluate was loaded onto the gel.

Gsp1-GDP or buffer alone (Fig. 6). Theamino-terminally truncated form of Psel (labeled as *), which lacks the Ran-binding domain (data not shown), does not dissociate from Pho4 ${ }^{\mathrm{WT}}$-zz after incubation with Gspl-GTP (Fig. 6, lanes 4-6). These data are consistent with a model in which Pho4 binds Psel in the cytoplasm and is released in the nucleus by the binding of Gsp1-GTP to Psel. These results provide further support for the functional relevance of the interaction between Pho4 and Psel.

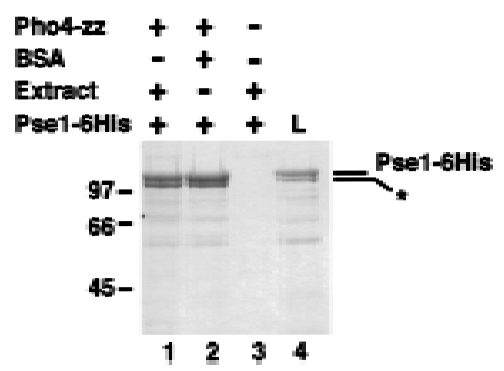

Figure 5. Pho4 interacts directly with Psel. Pho4 ${ }^{\mathrm{WT}}$-zz bound to IgG-Sepharose beads was incubated with Psel-6His purified from $\mathrm{E}$. coli in the presence of either yeast extract or BSA. The resin was washed extensively and proteins bound to $\mathrm{Pho}^{\mathrm{WT}}-\mathrm{Zz}$ were eluted with $1 \mathrm{M} \mathrm{M} \mathrm{gCl}_{2}$. Eluted proteins were precipitated, separated on $7.8 \%$ SDS-PAGE, and visualized by staining with Coomassie blue. A pproximately $50 \%$ of the Psel-6His preparation consists of an amino-terminally truncated form of Psel $\left(^{*}\right)$. (Lane 1) Psel-6His bound to Pho4 ${ }^{\mathrm{WT}}-\mathrm{zz}$ in the presence of whole cell extract (WCE); (lane 2) Pse1-6His bound to Pho4 ${ }^{\mathrm{WT}}$ $\mathrm{zz}$ in the presence of BSA; (lane 3) Psel-6His bound to IgGSepharose beads al one in the presence of WCE; (lane 4) $4 \%$ of the load. Half of the $1 \mathrm{M} \mathrm{M} \mathrm{gCl}_{2}$ eluate was loaded onto the gel.
Phosphorylation of Pho4 regulates its association with Psel

Because phosphorylation regulates the nuclear localization of Pho4, we sought to determine the effect of phosphorylation on the interaction of Pho4 with Psel.

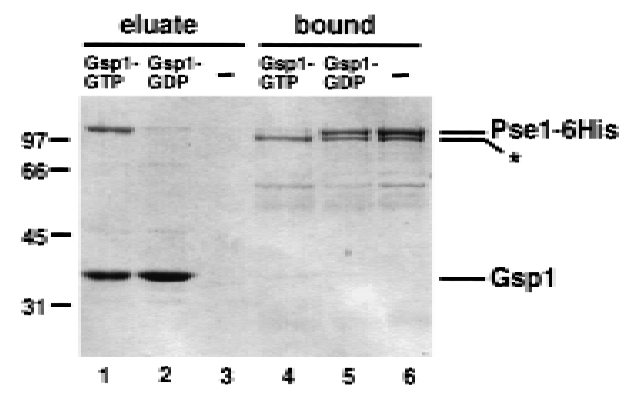

Figure 6. Gsp1-GTP dissociates the Pho4-Psel complex. Purified Psel-6His and Pho4 ${ }^{\mathrm{WT}}$-zz were incubated and the PselPho4 $^{\mathrm{WT}}$-zz complex was purified with IgG-Sepharose beads. The resin was washed extensively, split into three equal parts, and incubated with Gsp1-GTP, Gspl-GDP, or buffer al one. Proteins released during this treatment were collected as the eluate. The Pho4 ${ }^{\mathrm{WT}}$-zz resin was washed once with IgG buffer, and proteins bound to $\mathrm{Pho}^{\mathrm{WT}}-\mathrm{zz}$ were eluted with $1 \mathrm{M} \mathrm{M} \mathrm{gCl}_{2}$ and precipitated (bound fraction). Proteins were separated on $10 \%$ SDS-PAGE and visualized by staining with Coomassie blue. Lanes 1,4) Gsp1-GTP; (lanes 2,5) Gsp1-GDP; (lanes 3,6) buffer al one. One-third of the el uate and one-half of the bound proteins were loaded onto the gel. The amino-terminal ly truncated form of Psel-6His (*), which cannot bind Ran-GTP (data not shown), is not dissociated from Pho $4^{\mathrm{WT}}$-zz by incubation with GsplGTP. 
Pho4 ${ }^{\mathrm{WT}}-\mathrm{zz}$ was purified from E. coli and either phosphorylated in vitro with a yeast extract containing the Pho80-Pho85 cyclin-CDK complex or mock phosphorylated by incubating with yeast extract in the absence of ATP. Pho4 can be efficiently phosphorylated in vitro and the sites of phosphorylation utilized in vitro and in vivo are indistinguishable (Kaffman et al. 1994). Unphosphorylated and phosphorylated Pho $4^{\mathrm{WT}}$-zz were purified with IgG Sepharose beads and incubated with yeast extract containing Psel-GFP. The resin was washed, and proteins bound to Pho $4^{\mathrm{WT}}$-zz were eluted and analyzed by SDS-PAGE followed by immunoblotting with an antiGFP antibody (Fig. 7A). We find that Pho4 ${ }^{\mathrm{WT}}$-zz interacts preferentially with Psel in its unphosphorylated state.

As a control, we performed the same experiment with Pho4 ${ }^{\text {SA }}$, a mutant Pho4 containing al anine substitutions at the sites of phosphorylation. We find that phosphorylated and mock-phosphorylated Pho4 ${ }^{\mathrm{SA}}$-zz have a similar affinity for Psel-GFP, indicating that the difference in binding we observe between phosphorylated and unphosphorylated Pho4 is the result of specific phosphorylation at the sites utilized by Pho80-Pho85 (Fig. 7A, lanes 3,4). Moreover, phosphorylated and unphosphorylated Pho4 ${ }^{\mathrm{WT}}-\mathrm{zz}$ and $\mathrm{Pho} 4^{\mathrm{SA}}-\mathrm{zz}$ bind Pho85 with the same affinity (data not shown).

To determine if the preferential binding of unphosphorylated Pho4 to Psel is mediated by proteins in the yeast extract, we compared binding of purified Psel$6 \mathrm{His}$ with purified phosphorylated and unphosphorylated Pho4 ${ }^{\mathrm{WT}}-\mathrm{zz}$ (Fig. 7B). We find that purified Psel-
$6 \mathrm{H}$ is binds preferentially to unphosphorylated Pho4, suggesting that phosphorylation of Pho4 reduces its intrinsic affinity for Psel. These data suggest that phosphorylation of Pho4 regulates its import into the nucleus by preventing its interaction with Psel.

\section{Discussion}

The subcellular localization of Pho4 is regulated by phosphorylation in response to changes in the extracelIular concentration of inorganic phosphate. Pho4 is phosphorylated and localized predominantly to the cytoplasm when yeast are grown in phosphate-rich medium, and it is unphosphorylated and concentrated in the nucleus when yeast are starved for phosphate. We wished to determine how phosphorylation of Pho4 regulates its nucleocytoplasmic transport and to identify the machinery that moves Pho4 into and out of the nucleus. We demonstrate here that Psel is the import receptor for Pho4 and that phosphorylation of Pho4 di rectly regulates its association with Psel, providing a mechanism by which phosphorylation may regulate import of Pho4 in vivo.

Although previous studies have suggested a function for Psel in nucleocytopl asmic transport, its exact role is unclear. Psel is an essential gene, suggesting that it transports cargo whose proper l ocal ization is requi red for vegetative growth (Chow et al. 1992; Seedorf and Silver 1997). On the basis of the following data, Psel/Kap121 was proposed to play a role in both ribosomal protein import and in mRN A export: (1) mRN A export is defec-
Figure 7. Phosphorylated Pho4 has reduced affinity for Psel. (A) Phosphorylation affects binding of Pho4 to Psel in an extract. Purified $\mathrm{PhO}^{\mathrm{WT}}-\mathrm{zz}$ and $\mathrm{Pho}^{\mathrm{SA}}-\mathrm{zz}$, a mutant containing serine-to-al anine substitutions at the sites of phosphorylation, were phosphorylated or mock phosphorylated in vitro in an extract containing the Pho80-Pho85 cyclin-CDK complex. zz-Containing proteins were purified from the extract with IgG-Sepharose beads, washed extensively, and incubated with extract containing PselGFP. The resin was washed and proteins bound to $\mathrm{Pho} 4^{\mathrm{WT}}-\mathrm{Zz}$ and $\mathrm{Pho} 4^{\mathrm{SA}}-\mathrm{Zz}$ were eluted with $1 \mathrm{M} \mathrm{M} \mathrm{gCl}$. Eluted proteins were precipitated, separated on $7.8 \%$ SDS-PAGE, transferred to PVDF membrane, and visualized by immunoblotting with anti-GFP monoclonal antibodies (top). To ensure that the same amount of Pho4 was immobilized on IgG-Sepharose, Pho4-zz proteins were eluted from IgG-Sepharose with acetic acid, separated on a 7.8\% SDS-polyacrylamide gel, and visualized by staining with Coomassie blue (bottom). (Lane 1) Mock-phosphorylated Pho4 ${ }^{\text {WT }}$-zz (U); (lane 2) phosphorylated Pho4 ${ }^{\mathrm{WT}}$-zz (P); (lane 3) mock-phosphorylated Pho4 ${ }^{\mathrm{SA}}$-zz; (lane 4) phosphorylated Pho4 ${ }^{\mathrm{SA}}$-zz. Phosphorylation by Pho80-Pho85 causes $\mathrm{Pho}^{\mathrm{WT}}$-zz to migrate slower than unphosphorylated Pho4 ${ }^{\mathrm{WT}}-\mathrm{zz}$ in SDS-PAGE. (B) Phosphorylation affects Pho4 binding to purified Psel. Pho4 ${ }^{\mathrm{WT}}$-zz was phosphorylated or mock phosphorylated and the immobilized proteins were incubated with Psel-6His purified from E. coli. The resin was washed and proteins bound to Pho $4^{\mathrm{WT}}$-zz were eluted with $1 \mathrm{M} \mathrm{M} \mathrm{gCl} 2$. Eluted proteins were precipitated, separated on a 7.8\% SDS-polyacrylamide gel, and visualized by staining with silver (top). To ensure that the same amount of Pho4 was immobilized on IgG-Sepharose, Pho4 ${ }^{\mathrm{WT}}$-zz proteins were eluted from IgG-Sepharose with acetic acid, separated by $7.8 \%$ SDS-PAGE, and visualized by staining with Coomassie blue (bottom). (Lane 1) Mock-phosphorylated Pho4 ${ }^{\text {WT }}$-zz; (lane 2) phosphorylated Pho4 ${ }^{\mathrm{WT}}-\mathrm{zz}$; (lane 3 ) IgG-Sepharose beads al one $(-)$. (*) Truncated form of Psel. 
tive in the psel-1 kap123 $\Delta$ double mutant, but not the kap123s or pse1-1 mutant (Seedorf and Silver 1997); (2) the kap123 $\Delta$ strain is defective in import of the ribosomal protein L25 (Rout et al. 1997; Schlenstedt et al. 1997) and that defect can be suppressed by overexpression of PSE1 (Rout et al. 1997); and (3) in yeast extract, Kap123 binds to the ribosomal protein L25 and Psel can bind to L25, but only in the absence of Kap123 (Rout et al. 1997; Schlenstedt et al. 1997). These data are consistent with Kap123 being an import receptor for ribosomal proteins and with Psel playing a partially redundant role in ribosomal protein import. The mRNA export defect observed in the psel-1 kap123s double mutant may be indirect, as Psel clearly has a direct role in protein import.

We have demonstrated that nuclear import of Pho4 requires PSE1. Pho4 is the first cargo whose import is dependent exclusively on the function of Psel. Our results, in combination with previous studies, allow us to ascribe unique and separate functions to Psel and Kap123, as the kap123s strain is not defective in Pho4 import, nor does Kap123 interact with Pho4. The essential role for Psel in transport remains unclear, because cells lacking Pho4 or exhibiting defects in Pho4 localization do not have growth defects when grown in rich medium. The identification of a 27 amino acid peptide within Pho4 that is targeted to the nucleus in a PSE1dependent manner should facilitate the establishment of a consensus NLS recognized by Psel. This consensus sequence may lead to the identification of other Psel cargoes, providing a better understanding of its essential role in vegetative growth.

We have shown that phosphorylation of Pho4 reduces its affinity for Psel and that this reduction in affinity is a direct consequence of phosphorylation and is not mediated by other proteins in yeast extract. Remarkably, the N LS in Pho4 contains a single site of phosphorylation by Pho80-Pho85. It will be of interest to determine the contribution of individual phosphorylation sites to the regulation of the interaction with Psel. In addition, we wish to understand the structural effect that phosphorylation has on the ability of Pho4 to interact with Psel.

The subcel lular local ization of many proteins, including the transcriptional regulators NF-AT, Migl, Swi5, and Swi6, appears to be regulated by phosphorylation in response to either cell cycle position or extracellular signals (Moll et al. 1991; Sidorova et al. 1995; Beals et al. 1997; De Vit et al. 1997). The role of phosphorylation in regulation of Iocalization is not understood at a mechanistic level in any of these cases. The cell cycle regulated localization and phosphorylation of the yeast transcription factor Swi5 has striking parallels with the regulation of Pho4. In both systems, phosphorylation of a transcription factor by a cyclin-CDK complex results in the localization of the transcription factor to the cytoplasm. For Swi5, a region of the protein containing sites of phosphorylation by the CDK Cdc28 has been shown to be both necessary and sufficient for cell cycle-regulated localization (Moll et al. 1991). However, it is unclear if the regulated localization of Swi5 reflects regulation of import and/or export. Additionally, it is not clear if phosphorylation of Swi5 regulates its association with a transport receptor, with an adapter protein, or with a nuclear or cytoplasmic anchor.

Phosphorylation of a fusion protein containing the SV40 large $T$ antigen N LS has been shown to affect its nuclear import by modulating its interaction with importin $\alpha$ (Jans et al. 1991; Xiao et al. 1996; Hubner et al. 1997). However, these phosphorylation events have not been shown to occur in vivo, nor have they been observed to regulate the nuclear import of full-length SV40 large $T$ antigen. Our work provides a simple demonstration of how phosphorylation of a protein by a physiologically relevant kinase modifies its association with a transport receptor. This change in binding affinity could regulate the rate of nuclear import, thereby leading to a change in the nucleocytoplasmic localization of the cargo.

Previously, a correl ation between the phosphorylation state of a protein and its cytoplasmic compartmentalization has been interpreted as evidence for regulated import. The discovery of nuclear export pathways has led to the understanding that both nuclear import and/or export are potential points of regulation. The regulated localization of Pho4 in response to extracellular concentrations of inorganic phosphate is likely to reflect control of both import and export of Pho4. Data presented in this manuscript suggest that import of Pho4 is regulated by phosphorylation and our unpublished studies suggest that export of Pho4 also is regulated by phosphorylation. An understanding of how phosphorylation of Pho4 leads to a change in its subcel lular localization will require an experimental dissection of the effect of phosphorylation on the rates of import and export.

We propose that phosphorylation of a transcription factor in response to an environmental cue acts as a molecular switch, inhibiting import and, at the same time, promoting export. Blocking import prevents further nuclear entry of a transcription factor, whereas enhancing export l eads to a rapi d elimination of residual nucl ear activity. This type of molecular switch allows cells to utilize nucl eocytopl asmic local ization of a transcription factor as a way to regulate gene expression in a rapid and efficient way.

\section{Materials and methods}

Yeast strains and plasmids

Yeast strains were grown in YEPD or synthetic (SD) medium supplemented with amino acids (Sherman 1991) (except in phosphate starvation assays; see below). pho4 $4:$ TRP1 (EY 0130) and pho4s::TRP1 pho80 $\Delta::$ HIS3 (EY 0219) yeast strains derived from K699 ( $N$ asmyth et al. 1990) were generated by standard gene replacement techniques (Rothstein 1991). PSY 580, pse1-1, kap123s have been described previously (Seedorf and Silver 1997). Yeast transformations were performed by the lithium acetate method essentially as described (Guthrie and Fink 1991). 
pACPHO4-GFP (EB0347) was constructed as follows. First, the $\mathrm{PHO} 4$ promoter (nucleotides -323 to -1 upstream of the ATG) was amplified by PCR and subcloned into pRS316-GFP, which contains GFP ${ }^{565 T}$ (Heim et al. 1995) cloned into the EcoRI and BamHI sites of pRS316 (Sikorski and Hieter 1989), to generate pPHO4pr-GFP (EB0346). The entire PHO 4 coding region amplified by PCR was then subcloned in front of GFP in pRS316-GFP as a BglII-EcoRI fragment to generate pACPHO4GFP. pACPHO4 ${ }^{\mathrm{SA}}$-GFP (EB0356) is identical to pACPHO4GFP except that there are five serine-to-al anine substitutions at the sites of phosphorylation by Pho80-Pho85 (O'N eill et al. 1996). pPHO4-GFP 3 (EB0757) was constructed by amplifying two additional copies of the complete GFP ${ }^{565 T}$ gene which were cloned into $\mathrm{pPHO}$ 4-GFP as M fel-EcoRI fragments. pPHO4-GFP derivatives $\left[\mathrm{pPHO}_{2-247}-\mathrm{GFP}\right.$ (EB0350), $\mathrm{pPHO}_{2-94}-\mathrm{GFP}_{3}$ (EB0824), $\mathrm{pPHO}_{248-312}-\mathrm{GFP}_{3}$ (EB0825), $\mathrm{pPHO}_{\Delta 95-162}-\mathrm{GFP}$ (EB0364), pPHO4 ${ }_{\Delta 172-192}$-GFP (EB0365), pPHO4 ${ }_{\Delta 141-165}$-GFP (EB0823), pPHO4 ${ }_{\triangle 157-164}-\mathrm{GFP}$ (EB0383), pPHO4 ${ }_{95-166}-\mathrm{GFP}_{3}$ (EB0832), pPHO4 $4_{140-171}-\mathrm{GFP}_{3}$ (EB0834), $\mathrm{pPHO}_{156-171}-\mathrm{GFP}_{3}$ (EB0835), pPHO4 ${ }_{140-166}-\mathrm{GFP}_{3}$ (EB0836)] were constructed by amplifying $\mathrm{PHO} 4$ from $\mathrm{pAC} 312$ with the appropriate primers and subcloning the resulting fragments into either pACPHO4GFP or pPHO4-GFP 3 , replacing full-length $\mathrm{PHO} 4$. Further information on the construction of PHO4-GFP derivatives is available upon request. pT 7-PHO $4^{\mathrm{WT}}$-zz (EB0801) was generated by amplifying zz from pTL27 (Lafontaine and Tollervey 1996) and was used to replace the EcoRI-BamHI fragment containing GFP in pACPHO4-GFP. The Ncol-BamHI fragment containing Pho $4^{\mathrm{WT}}-\mathrm{z}$ was then cloned into $\mathrm{pET} 16 \mathrm{~b}$ ( $\mathrm{N}$ ovagen) to generate pT 7-PHO $4^{\mathrm{WT}}-\mathrm{zZ}$. pT 7-PHO $4^{\mathrm{SA}}-\mathrm{ZZ}$ (EB0814) is identical to $\mathrm{pT} 7-\mathrm{PHO} 4^{\mathrm{WT}}-\mathrm{zz}$ except that there are five serine-toalanine substitutions at the sites of phosphorylation by Pho80Pho85 (O'N eill et al. 1996). pT 7-PHO4 ${ }_{\Delta 157-164}$-ZZ (EB0769) was generated by first subcloning the EcoRI-BamHI fragment containing $z z$ from pPHO4-zz into $\mathrm{pPHO}_{\Delta 157-164}-\mathrm{GFP}$. Next, $\mathrm{PHO}_{\Delta 157-164}-\mathrm{ZZ}$ was subcloned as an Ncol-BamHI fragment into pET 16b (N ovagen). pPSE1-GFP (pPS1069), pSXM 1-GFP (pPS1117), and pKAP123-GFP (pPS1070) have been described previously (Seedorf and Silver 1997). pPSE1-6His (EB0815) was constructed by PCR amplifying PSE1 from the yeast genome (Promega) and subcloning the fragment into the BamHI site of pQE60 (Qiagen) to generate carboxy-terminally His-tagged Psel. pSH101-1 (a gift from Shai Shaham, University of California, San Francisco) consists of GSP1 fused to three copies of the myc epitope tag under the control of the GSP1 promoter in pRS303 (Sikorski and Hieter 1989). pT 7-myc-GSP1 was constructed by amplifying mycGSP1 from pSH101-1 and cloning the amplified fragment into the $\mathrm{N}$ del and Xhol sites of pAED4. All constructs were verified by sequencing except pPSE1-6His which was shown to complement a psel $\Delta$ mutant (data not shown).

\section{Phosphate starvation assay and microscopy}

Yeast was grown overnight at $25^{\circ} \mathrm{C}$ in SD medium supplemented with amino acids (high-phosphate medium) and then diluted and grown to an $O D_{600}$ of 0.1-0.3. One milliliter of this culture was pelleted, and the pellet was resuspended in $50 \mu \mathrm{l}$ of high-phosphate medium for steady-state high-phosphate localization of GFP derivatives. Two microliters of the high-phosphate culture was placed on a microscope slide and GFP localization in live cultures was monitored by direct fluorescence. The remaining yeast culture was pelleted by centrifugation and washed twice with $10 \mathrm{ml}$ of water, once with $1 \mathrm{ml}$ of water, and resuspended in no-phosphate medium (SD dropout medium with potassium chloride replacing monobasic potassium phos- phate) to an $\mathrm{OD}_{600}$ of $0.1-0.3$. Yeast was grown in medium lacking phosphate for $30-45 \mathrm{~min}$ to starve the yeast for phosphate. One milliliter of phosphate-starved culture was pelleted and resuspended in $50 \mu \mathrm{l}$ of no phosphate medium. Two microliters of the starved culture was place on a microscope slide and GFP localization was monitored. All images documenting GFP localization were collected with a CCD camera using identical settings (Photometrics).

\section{Recombinant protein expression and purification}

Psel was expressed in E. coli with a $6 \mathrm{H}$ is tag at the carboxyl terminus. Bacterial cells (strain SG13009) containing the pPSE1-6His expression vector were grown in LB $+100 \mu \mathrm{g} / \mathrm{ml}$ carbenicillin $+25 \mu \mathrm{g} / \mathrm{ml}$ kanamycin to an $\mathrm{OD}_{600}$ of 0.6 , and expression was induced with $1 \mathrm{~mm} \mathrm{IPTG}$ for $3 \mathrm{hr}$ at room temperature. Cells were resuspended in lysis buffer $(30 \mathrm{~mm}$ Tris-Cl at $\mathrm{pH} 8,500 \mathrm{~mm} \mathrm{NaCl}, 0.05 \%$ Tween 20 , and $2 \mathrm{~mm} \beta$-mercaptoethanol) containing $30 \mathrm{~mm}$ imidazole and protease inhibitors ( $1 \mathrm{~mm}$ PM SF, $2 \mathrm{~mm}$ benzamidine, $1 \mu \mathrm{g} / \mathrm{ml}$ pepstatin A, $1 \mu \mathrm{g} / \mathrm{ml}$ leupeptin), lysed by sonication, and cleared by centrifugation at $17,000 \mathrm{rpm}$ in an SS34 rotor for $20 \mathrm{~min}$. The lysate containing the Psel-6His fusion protein was loaded on a $1 \mathrm{ml}$ of chelating $\mathrm{HiT}$ rap column (Pharmacia) at $1 \mathrm{ml} / \mathrm{min}$ in lysis buffer containing $30 \mathrm{~mm}$ imidazole and protease inhibitors and eluted with a 30 to $1000 \mathrm{~mm}$ imidazole gradient. Eluted proteins were dialyzed against $100 \mathrm{~mm} \mathrm{~N} \mathrm{aCl}, 30 \mathrm{~mm}$ Tris- $\mathrm{Cl}$ (pH 8). After dialysis, sorbitol was added to a final concentration of $250 \mathrm{~mm}$ and the purified protein was frozen in small aliquots and stored at $-80^{\circ} \mathrm{C}$. A pproximately $90 \%$ of the purified material contains an equal mixture of full-length Pse1-6His and a truncation product lacking part of the amino terminus. To express Myc-Gspl, E. coli (strain BL21) containing pT7-mycGspl was grown in $\mathrm{LB}+100 \mu \mathrm{g} / \mathrm{ml}$ carbenicillin to an $\mathrm{OD}_{600}$ of 0.6 , and expression was induced with $0.4 \mathrm{mM}$ IPTG for $3 \mathrm{hr}$ at room temperature. Cell pellet from 3 liters of culture was resuspended in $40 \mathrm{ml}$ of D-50 (20 mM KH ${ }_{2} \mathrm{PO}_{4}$ at pH 6.6, 10\% glycerol, $2 \mathrm{~mm} \mathrm{M} \mathrm{gCl}, 50$ $\mathrm{mM} \mathrm{KCl}, 1 \mathrm{~mm}$ DTT, $5 \mu \mathrm{M}$ GTP) containing protease inhibitors ( $1 \mathrm{~mm}$ PMSF, $2 \mathrm{~mm}$ benzamidine, $1 \mu \mathrm{g} / \mathrm{ml}$ pepstatin A, $1 \mu \mathrm{g} / \mathrm{ml}$ leupeptin), sonicated, and spun for $20 \mathrm{~min}$ in an SS34 rotor at 17,000 rpm. Extract was loaded onto a 10-ml SP Sepharose HR (Pharmacia) column at $2 \mathrm{ml} / \mathrm{min}$ and eluted with a 50 to 1000 $\mathrm{mm} \mathrm{KCl}$ gradient. Fractions containing $\mathrm{M}$ yc-Gspl were precipitated with $60 \%$ ammonium sulfate, resuspended in $1.5 \mathrm{ml}$ of F-50 (30 mM HEPES-KOH at pH 7.7, 8.7\% glycerol, $2 \mathrm{~mm}$ $\mathrm{M} \mathrm{gCl}_{2}, 5 \mu \mathrm{M} \mathrm{GTP}, 50 \mathrm{~mm} \mathrm{KCl}$ ) and loaded onto a Sephacryl S100 (Pharmacia) column equilibrated in F-50. Fractions containing Myc-Gspl were concentrated on a 2-ml Bio-Scale Q column (Bio-Rad), and the purified protein ( $>95 \%$ pure) was frozen in small aliqouts. To produce Pho4-zz fusion proteins, E. coli (strain BL21) containing the Pho4-zz expression vector was grown to $O D_{600}$ of 0.6 in $L B+100 \mu \mathrm{g} / \mathrm{ml}$ carbenicillin and induced with $0.4 \mathrm{~mm}$ IPTG for $3 \mathrm{hr}$ at room temperature. Cell pellet from 1 liter of culture was resuspended in $15 \mathrm{ml}$ of IgG buffer $(50 \mathrm{~mm}$ Tris- $\mathrm{Cl}$ at $\mathrm{pH} 7.5,150 \mathrm{~mm} \mathrm{NaCl}, 0.05 \%$ Tween 20, $5 \mathrm{~mm} \mathrm{M} \mathrm{gCl}$ ), sonicated, and spun for $1 \mathrm{hr}$ at $60,000 \mathrm{~g}$. Sucrose was added to a final concentration of $250 \mathrm{~mm}$, and the high-speed supernatant was frozen in $0.5-\mathrm{ml}$ aliquots. Pho4-zz proteins were purified by diluting this high-speed supernatant to $\sim 2 \mathrm{mg} / \mathrm{ml}$ in buffer B 0.1 (20 mM PIPES- $\mathrm{KOH}$ at pH 6.8, $1 \mathrm{~mm}$ EDTA, $10 \%$ glycerol, $100 \mathrm{~mm} \mathrm{~N} \mathrm{aCl}$ ) plus protease inhibitors (1 $\mathrm{mm}$ PMSF, $2 \mathrm{~mm}$ benzamidine, $1 \mu \mathrm{g} / \mathrm{ml}$ pepstatin A, $1 \mu \mathrm{g} / \mathrm{ml}$ leupeptin) and loaded onto a $1 \mathrm{ml}$ SP Sepharose HiTrap column (Pharmacia) at $1 \mathrm{ml} / \mathrm{min}$ and eluted with a $100-1000 \mathrm{~mm} \mathrm{NaCl}$ gradient. Fractions containing Pho4-zz ( $90 \%$ pure) were then frozen in small aliqouts. 


\section{Yeast extract preparation}

Yeast strain Y 57 was grown in $300 \mathrm{ml}$ of synthetic high-phosphate medium to an $O D_{600}$ of 1 , harvested, and washed with 20 $\mathrm{ml}$ of $\mathrm{H}_{2} \mathrm{O}$. Cells were resuspended in $2 \mathrm{ml}$ of IgG buffer containing protease inhibitors ( $1 \mathrm{mM}$ PMSF, $2 \mathrm{~mm}$ benzamidine, 1 $\mu \mathrm{g} / \mathrm{ml}$ pepstatin $\mathrm{A}, 1 \mu \mathrm{g} / \mathrm{ml}$ leupeptin) and transferred to a 2-ml screw-cap Eppendorf tube containing $\sim 1 \mathrm{ml}$ of $0.5-\mathrm{mm}$ acidwashed glass beads. Trapped air was removed and cells were lysed in a minibead beater (BioSpec Products) by use of $5 \times 1$ min strokes with a 1-min resting period on ice. The supernatant was transferred to a new Eppendorf tube and cl eared by spinning $2 \times 20 \mathrm{~min}$ at $4^{\circ} \mathrm{C}$ in a microcentrifuge at $14,000 \mathrm{rpm}$ and filtering through a $0.22-\mu \mathrm{m}$ filter. Glycerol was added to a final concentration of $10 \%$, and the extract was frozen at $-80^{\circ} \mathrm{C}$ in small aliqouts.

\section{Binding assay}

For the assay of $\mathrm{Pho}^{\mathrm{WT}}-\mathrm{zz}$ and $\mathrm{PhO}_{\Delta 157-164}-\mathrm{Zz}$ binding to Psel-GFP, Sxm1-GFP, and Kap123-GFP, saturating amounts of bacterial lysate from either Pho4 ${ }^{\mathrm{WT}}$-zz or $\mathrm{Pho}_{\Delta 157-164^{-}} \mathrm{Zz}$ were bound to $25 \mu \mathrm{l}$ of IgG-Sepharose by incubating for $90 \mathrm{~min}$ at $4^{\circ} \mathrm{C}$. The resin with bound Pho4-zz $(\sim 4 \mathrm{mg} / \mathrm{ml})$ was washed with IgG buffer plus protease inhibitors (1 mM PMSF, $2 \mathrm{~mm}$ benzamidine, $1 \mu \mathrm{g} / \mathrm{ml}$ pepstatin $A, 1 \mathrm{mg} / \mathrm{ml}$ leupeptin), followed by IgG buffer containing $1 \mathrm{M}$ of $\mathrm{N} \mathrm{aCl}$, and then re-equilibrated with IgG buffer. Immobilized Pho4-zz proteins were incubated for $3 \mathrm{hr}$ at $4^{\circ} \mathrm{C}$ with $1.65 \mathrm{mg}$ of total protein from a Y 57 extract expressing one of the importin $\beta$ family members tagged with GFP. The resin was washed extensively with IgG buffer and proteins bound to Pho4-zz proteins were eluted with IgG buffer containing $1 \mathrm{M} \mathrm{M} \mathrm{gCl}_{2}$ and concentrated with methanolchloroform precipitation. Pho4 ${ }^{\mathrm{WT}}$-zz proteins were el uted with 0.5 M HOAC (pH 3.4). For binding Pho4 ${ }^{\mathrm{WT}}$-zz to purified Psel$6 \mathrm{His}, \mathrm{Pho}^{\mathrm{WT}}-\mathrm{zz}$ was purified from bacterial lysate as described above and incubated with $50 \mu \mathrm{g}$ of purified Psel-6His in the presence of either $1.65 \mathrm{mg}$ of total protein from a Y 57 extract or $1.65 \mathrm{mg}$ of bovine serum al bumin (BSA) for $3 \mathrm{hr}$ at $4^{\circ} \mathrm{C}$. Samples were processed as described above. For binding of phosphorylated and unphosphorylated Pho4 ${ }^{\mathrm{WT}}-\mathrm{zz}$ to Psel-GFP in a yeast extract, $30 \mu \mathrm{g}$ of immobilized phosphorylated or unphosphorylated Pho4 ${ }^{\mathrm{WT}}$-zz was incubated with $1.65 \mathrm{mg}$ of protein from a Y57 extract containing Psel-GFP, and samples were processed as described above. For binding of Pho $4^{\mathrm{WT}}-\mathrm{zz}$ to purified Psel, $30 \mu \mathrm{g}$ of immobilized phosphorylated or unphosphorylated $\mathrm{Pho}^{\mathrm{WT}}$-zz was purified away from the yeast extract by incubating with $1 \mathrm{M} \mathrm{M} \mathrm{gCl}_{2}$ for $10 \mathrm{~min}$ at room temperature, reequilibrating with IgG buffer, and incubating further with $10 \mathrm{~nm}$ purified Psel-6His in the presence of $10 \%$ glycerol and $2 \mathrm{mg} / \mathrm{ml}$ BSA for $1 \mathrm{hr}$ at room temperature. The resin was washed extensively with IgG buffer, eluted with $1 \mathrm{M} \mathrm{M} \mathrm{gCl}_{2}$, and concentrated with methanol-chloroform precipitation.

\section{In vitro phosphorylation of Pho4-zz proteins}

Thirty micrograms of purified Pho $4^{\mathrm{WT}}-\mathrm{zz}$ or $\mathrm{Pho} 4^{\mathrm{SA}}-\mathrm{zz}$ was incubated with $\sim 1 \mathrm{mg}$ of yeast whole-cell extract containing $\mathrm{HA}$ Pho80 expressed from the GPD promoter for $1 \mathrm{hr}$ at room temperature in the presence of phosphatase inhibitors $(80 \mathrm{~mm} \beta$ glycerophosphate, $10 \mathrm{~mm} \mathrm{~N} \mathrm{aF,} 10 \mathrm{~nm}$ calyculin A), and protease inhibitors ( $1 \mathrm{~mm}$ PMSF, $2 \mathrm{~mm}$ benzamidine, $1 \mu \mathrm{g} / \mathrm{ml}$ leupeptin, $1 \mu \mathrm{g} / \mathrm{ml}$ pepstatin A), either in the presence of an ATP regenerating system ( $1 \mathrm{~mm}$ ATP, $5 \mathrm{~mm}$ creatine phosphate, $50 \mu \mathrm{g} / \mathrm{ml}$ creatine kinase), or in the absence of an ATP regenerating system (mock phosphorylation). The reaction was placed on ice, diluted with IgG buffer to $\sim 3 \mathrm{mg} / \mathrm{ml}$, and incubated with $25 \mu \mathrm{l}$ of IgG-Sepharose beads for $2 \mathrm{hr}$ at $4^{\circ} \mathrm{C}$. Bound Pho4-zz proteins were purified by extensive washes with IgG buffer followed by a wash with IgG buffer containing $1 \mathrm{M} \mathrm{N} \mathrm{aCl}$ and then re-equilibrated in IgG buffer for binding studies.

\section{Dissociation of the Pho4-Psel complex by Gspl-GTP}

Sixty micrograms of purified Psel-6His and $60 \mu \mathrm{g}$ of Pho $4^{\mathrm{WT}}-\mathrm{zz}$ were bound in a $240-\mu \mathrm{l}$ reaction for $1 \mathrm{hr}$ at $4^{\circ} \mathrm{C}$. Complex containing Psel-6His bound to Pho4 ${ }^{\mathrm{WT}}$ - $\mathrm{zz}$ was purified by incubating the reaction with $35 \mu \mathrm{l}$ of IgG-Sepharose beads for $2 \mathrm{hr}$ at $4^{\circ} \mathrm{C}$. The resin containing immobilized $\mathrm{Pho} 4^{\mathrm{WT}}-\mathrm{zz}$ bound to Psel was washed extensively with IgG buffer and split into three equal parts. One-third of the immobilized Pho4 ${ }^{\mathrm{WT}}-\mathrm{zz}$ bound to Psel was incubated with $10 \mu \mathrm{g}$ of purified Myc-Gspl loaded with GTP, one-third with $10 \mu \mathrm{g}$ of purified Myc-Gsp1 loaded with GDP, and one-third with buffer al one for $20 \mathrm{~min}$ at room temperature. Proteins released during this incubation period were collected (eluate), the resin was washed once with 0.5 $\mathrm{ml}$ of IgG buffer, bound proteins were eluted with $1 \mathrm{M} \mathrm{M} \mathrm{gCl}_{2}$, and concentrated with methanol-chloroform precipitation. Proteins were separated on a $10 \%$ SDS-polyacrylamide gel and visualized by staining with Coomassie blue.

Nucleotide loading of Myc-Gspl was performed as follows. Purified Myc-Gspl $(0.67 \mathrm{mg} / \mathrm{ml})$ was incubated in the presence of $20 \mathrm{~mm}$ EDTA, $2 \mathrm{~mm}$ GTP or GDP, and $2 \mathrm{~mm}$ DTT for $1 \mathrm{hr}$ at room temperature. $\mathrm{M} \mathrm{gCl}_{2}$ was added to a final concentration of $50 \mathrm{~mm}$ and the reaction was incubated further on ice for $20 \mathrm{~min}$. Unbound nucl eotides were removed by loading the sample over a Bio-Spin P-6 spin column (Bio-Rad) equilibrated in F-50 and the Myc-Gspl was frozen in small aliquots.

\section{Acknowledgments}

We thank Pamela Silver for the pse1-1, kap123 4 , sxm1 $1 \Delta$, and PSY580 yeast strains, John Aitchison for the kap104 $4^{\text {ts }}$ strain, Molly Fitzgerald-Hayes for the csel mutant strain, and Karsten Weis and Katrin Stade for xpol-1. We thank Pamela Silver for the plasmids expressing Psel-GFP, SXM 1-GFP and Kap123GFP, Karsten Weis for pTL27 and Shai Shaham for pSH101-1. We also thank Karsten Weis and members of the E.K.O. and Guthrie laboratories for their critical comments on this work. This work was supported by a $\mathrm{N}$ ational Science Foundation Presidential Faculty Fellow Award and a grant from the David and Lucile Packard Foundation (to E.K.O.). A.K. was supported by the Medical Scientist Training Program.

The publication costs of this article were defrayed in part by payment of page charges. This article must therefore be hereby marked 'advertisement' in accordance with 18 USC section 1734 solely to indicate this fact.

\section{References}

Aitchison, J.D., G. Blobel, and M.P. Rout. 1996. Kap104p: A karyopherin involved in the nuclear transport of messenger RN A binding proteins. Science 274: 624-627.

Beals, C.R., N.A. Clipstone, S.N. Ho, and G.R. Crabtree. 1997. N uclear localization of N F-ATc by a cal cineurin-dependent, cyclosporin-sensitive intramolecular interaction. Genes \& Dev. 11: 824-834.

Chow, T.Y., J.J. Ash, D. Dignard, and D.Y. Thomas. 1992. Screening and identification of a gene, PSE-1, that affects protein secretion in Saccharomyces cerevisiae. J. Cell Sci. 101: 709-719. 
De Vit, M.J., J.A. Waddle, and M. Johnston. 1997. Regulated nuclear translocation of the $\mathrm{Migl}$ glucose repressor. Mol. Biol. Cell 8: 1603-1618.

Fornerod, M., M. Ohno, M. Yoshida, and I.W. Mattaj. 1997. CRM 1 is an export receptor for leucine-rich nuclear export signals. Cell 90: 1051-1060.

Fukuda, M., S. Asano, T. N akamura, M. Adachi, M. Yoshida, M. Yanagida, and E. Nishida. 1997. CRM 1 is responsible for intracellular transport mediated by the nuclear export signal. Nature 39: 308-311.

Gaits, F., G. Degols, K. Shiozaki, and P. Russell. 1998. Phosphorylation and association with the transcription factor atf1 regulate localization of Spc1/Sty1 stress-activated kinase in fission yeast. Genes \& Dev. 12: 1464-1473.

Gorlich, D., S. Prehn, R.A. Laskey, and E. Hartmann. 1994. Isolation of a protein that is essential for the first step of nuclear protein import. Cell 79: 767-778.

Gorlich, D., S. Kostka, R. Kraft, C. Dingwall, R.A. Laskey, E. Hartmann, and S. Prehn. 1995a. Two different subunits of importin cooperate to recognize nuclear local ization signals and bind them to the nuclear envelope. Curr. Biol. 5: 383392.

Gorlich, D., F. Vogel, A.D. Mills, E. Hartmann, and R.A. Laskey. 1995b. Distinct functions for the two importin subunits in nuclear protein import. Nature 377: 246-248.

Gorlich, D., N. Pante, U. Kutay, U. Aebi, and F.R. Bischoff. 1996. Identification of different roles for RanGDP and RanGTP in nuclear protein import. EMBO J. 15: 5584-5594.

Gorlich, D., M. Dabrowski, F.R. Bischoff, U. Kutay, P. Bork, E. Hartmann, S. Prehn, and E. Izaurral de. 1997. A novel class of RanGTP binding proteins. J. Cell Biol. 138: 65-80.

Guthrie, C. and G.R. Fink. 1991. Guide to yeast genetics and molecular biology. In Methods in enzymology 199: 186.

Heim, R., A.B. Cubitt, and R.Y. Tsien. 1995. Improved green fluorescence. Nature 373: 663-664.

Hopper, A.K., L.D. Schultz, and R.A. Shapiro. 1980. Processing of intervening sequences: $A$ new yeast mutant which fails to excise intervening sequences from precursor tRNAs. Cell 19: $741-751$.

Hubner, S., C.Y. Xiao, and D.A. Jans. 1997. The protein kinase CK2 site (Ser111/112) enhances recognition of the simian virus 40 large $\mathrm{T}$-antigen nuclear localization sequence by importin. J. Biol. Chem. 272: 17191-17195.

Imamoto, N., T. Tachibana, M. M atsubae, and Y. Yoneda. 1995. A karyophilic protein forms a stable complex with cytoplasmic components prior to nucl ear pore binding. J. Biol. Chem. 270: 8559-8565.

Izaurralde, E., U. Kutay, C. von Kobbe, I.W. Mattaj, and D. Gorlich. 1997. The asymmetric distribution of the constituents of the Ran system is essential for transport into and out of the nucleus. EMBO J. 16: 6535-6547.

Jans, D.A. and S. Hubner. 1996. Regulation of protein transport to the nucleus: Central role of phosphorylation. Physiol. Rev. 76: 651-685.

Jans, D.A., M.J. Ackermann, J.R. Bischoff, D.H. Beach, and R. Peters. 1991. p34cdc2-mediated phosphorylation at T 124 inhibits nuclear import of SV- $40 \mathrm{~T}$ antigen proteins. J. Cell Biol. 115: 1203-1212.

Kadowaki, T., S. Chen, M. Hitomi, E. Jacobs, C. Kumagai, S. Liang, R. Schneiter, D. Singleton, J. Wisniewska, and A.M. Tartakoff. 1994. Isolation and characterization of Saccharomyces cerevisiae mRNA transport-defective (mtr) mutants. J. Cell Biol. 126: 649-659.

Kaffman, A., I. Herskowitz, R. Tjian, and E.K. O'Shea. 1994. Phosphorylation of the transcription factor $\mathrm{PHO} 4$ by a cycIin-CDK complex, PHO80-PH085. Science 263: 1153-1156.
Kalderon, D., W.D. Richardson, A.F. M arkham, and A.E. Smith. 1984. Sequence requirements for nuclear location of simian virus 40 large-T antigen. Nature 311: 33-38.

Khokhlatchev, A.V., B. Canagarajah, J. Wilsbacher, M. Robinson, M. Atkinson, E. Goldsmith, and M.H. Cobb. 1998. Phosphorylation of the MAP kinase ERK2 promotes its homodimerization and nuclear translocation. Cell 93: 605-615.

Kudo, N., S. Khochbin, K. Nishi, K. Kitano, M. Yanagida, M. Yoshida, and S. Horinouchi. 1997. Molecular cloning and cell cycle-dependent expression of mammalian CRM1, a protein involved in nuclear export of proteins. J. Biol. Chem. 272: 29742-29751.

Kutay, U., F.R. Bischoff, S. Kostka, R. Kraft, and D. Gorlich. 1997. Export of importin al pha from the nucleus is mediated by a specific nuclear transport factor. Cell 90: 1061-1071.

Kutay, U., G. Lipowsky, E. Izaurral de, F.R. Bischoff, P. Schwarzmaier, E. Hartmann, and D. Gorlich. 1998. Identification of a tRN A-specific nuclear export receptor. Mol. Cell 1: 359369.

Lafontaine, D. and D. Tollervey. 1996. One-step PCR mediated strategy for the construction of conditionally expressed and epitope tagged yeast proteins. Nucleic Acids Res. 24: 34693471.

Latimer, M., M.K. Ernst, L.L. Dunn, M. Drutskaya, and N.R. Rice. 1998. The $\mathrm{N}$-terminal domain of IkappaB al pha masks the nuclear localization signal(s) of p50 and c-Rel homodimers. Mol. Cell. Biol. 18: 2640-2649.

Magbanua, J.P., N. Ogawa, S. Harashima, and Y. Oshima. 1997. The transcriptional activators of the PHO regulon, Pho4p and Pho2p, interact directly with each other and with components of the basal transcription machinery in Saccharomyces cerevisiae. J. Biochem. (Tokyo) 121: 1182-1189.

Moll, T., G. Tebb, U. Surana, H. Robitsch, and K. N asmyth. 1991. The role of phosphorylation and the CDC28 protein kinase in cell cycle- regulated nuclear import of the S. cerevisiae transcription factor SWI5. Cell 66: 743-758.

Moroianu, J., M. Hijikata, G. Blobel, and A. Radu. 1995. Mammalian karyopherin alpha 1 beta and alpha 2 beta heterodimers: Alpha 1 or al pha 2 subunit binds nuclear localization signal and beta subunit interacts with pepti de repeatcontaining nucleoporins. Proc. Natl. Acad. Sci. 92: 6532-6536.

Moroianu, J., G. Blobel, and A. Radu. 1996. Nuclear protein import: Ran-GTP dissociates the karyopherin al phabeta heterodimer by displacing al pha from an overlapping binding site on beta. Proc. Natl. Acad. Sci. 93: 7059-7062.

Nakielny, S. and G. Dreyfuss. 1997. Nuclear export of proteins and RN As. Curr. Opin. Cell Biol. 9: 420-429.

Nasmyth, K., G. Adolf, D. Lydall, and A. Seddon. 1990. The identification of a second cell cycle control on the $\mathrm{HO}$ promoter in yeast: Cell cycle regulation of SW15 nuclear entry. Cell 62: 631-647.

N eville, M., F. Stutz, L. lee, L.I. Davis, and M. Rosbash. 1997. The importin-beta family member Crmlp bridges the interaction between Rev and the nuclear pore complex during nuclear export. Curr. Biol. 7: 767-775.

N ewmeyer, D.D. and D.J. Forbes. 1988. N uclear import can be separated into distinct steps in vitro: Nuclear pore binding and translocation. Cell 52: 641-653.

Nigg, E.A. 1997. N ucleocytoplasmic transport: Signals, mechanisms and regulation. Nature 386: 779-787.

Ogawa, N. and Y. Oshima. 1990. Functional domains of a positive regulatory protein, $\mathrm{PHO} 4$, for transcriptional control of the phosphatase regulon in Saccharomyces cerevisiae. Mol. Cell. Biol. 10: 2224-2236. 
Ohtsubo, M., H. Okazaki, and T. Nishimoto. 1989. The RCC1 protein, a regulator for the onset of chromosome condensation locates in the nucleus and binds to DNA. J. Cell Biol. 109: 1389-1397.

O'N eill, E.M., A. Kaffman, E.R. Jolly, and E.K. O'Shea. 1996. Regulation of $\mathrm{PHO} 4$ nuclear localization by the $\mathrm{PHO} 80$ PHO85 cyclin-CDK complex. Science 271: 209-212.

Oshima, Y. 1997. The phosphatase system in Saccharomyces cerevisiae. Genes Genet. Syst. 72: 323-334.

Ossareh-N ayari, B., F. Bacheline, and C. Dargemmt. 1997. Evidence for a role of CRM 1 in signal-mediated nuclear protein export. Science 278: 141-144.

Rexach, M. and G. Blobel. 1995. Protein import into nuclei: Association and dissociation reactions involving transport substrate, transport factors, and nucleoporins. Cell 83: 683692.

Richardson, W.D., A.D. Mills, S.M. Dilworth, R.A. Laskey, and C. Dingwall. 1988. N uclear protein migration involves two steps: Rapid binding at the nuclear envelope followed by slower translocation through nuclear pores. Cell 52: 655664.

Rothstein, R. 1991. Targeting, disruption, replacement, and allele rescue: Integrative DN A transformation in yeast. Methods Enzymol. 194: 281.

Rout, M.P., G. Blobel, and J.D. Aitchison. 1997. A distinct nuclear import pathway used by ribosomal proteins. Cell 89: 715-725.

Schlenstedt, G., E. Smirnova, R. Deane, J. Sol sbacher, U. Kutay, D. Gorlich, H. Ponstingl, and F.R. Bischoff. 1997. Yrb4p, a yeast ran-GTP-binding protein involved in import of ribosomal protein L25 into the nucleus. EMBO J. 16: 6237-6249.

Schneider, K.R., R.L. Smith, and E.K. O'Shea. 1994. Phosphateregulated inactivation of the kinase $\mathrm{PHO} 80-\mathrm{PHO} 85$ by the CDK inhibitor PHO81. Science 266: 122-126.

Seedorf, M. and P.A. Silver. 1997. Importin/karyopherin protein family members required for mRNA export from the nucleus. Proc. Natl. Acad. Sci. 94: 8590-8595.

Sherman, F. 1991. Getting started with yeast. Methods Enzymol. 194: 3.

Sidorova, J.M., G.E. Mikesell, and L.L. Breeden. 1995. Cell cycle-regulated phosphorylation of Swi 6 controls its nuclear localization. Mol. Biol. Cell 6: 1641-1658.

Sikorski, R.S. and P. Hieter. 1989. A system of shuttle vectors and yeast host strains designed for efficient manipulation of DN A in Saccharomyces cerevisiae. Genetics 122: 19-27.

Stade, K., C.S. Ford, C. Guthrie, and K. Weis. 1997. Exportin 1 (Crm1p) is an essential nuclear export factor. Cell 90: 10411050.

Toone, W.M., S. Kuge, M. Samuels, B.A. Morgan, T. Toda, and N. Jones. 1998. Regulation of the fission yeast transcription factor papl by oxidative stress: Requirement for the nuclear export factor $\mathrm{crm} 1$ (Exportin) and the stress-activated MAP kinase Sty1/Spc1. Genes \& Dev. 12: 1453-1463.

Weis, K. 1998. Importins and exportins: How to get in and out of the nucleus. Trends Biochem. Sci. 23: 157-196.

Weis, K., I.W. Mattaj, and A.I. Lamond. 1995. Identification of hSRP1 al pha as a functional receptor for nuclear local ization sequences. Science 268: 1049-1053.

Wen, W., J.L. Meinkoth, R.Y. Tsien, and S.S. Taylor. 1995. Identification of a signal for rapid export of proteins from the nucleus. Cell 82: 463-473.

Williams, S.C., N.D. Angerer, and P.F. Johnson. 1997. C/EBP proteins contain nuclear localization signals imbedded in their basic regions. Gene Expr. 6: 371-385.

Xiao, C.Y., S. Hubner, R.M. Elliot, A. Caon, and D.A. Jans. 1996. A consensus CAM P-dependent protein kinase (PK-A) site in place of the $\mathrm{CcN}$ motif casein kinase II site simian virus 40 large T-antigen confers PK-A-mediated regulation of nuclear import. J. Biol. Chem. 271: 6451-6457.

Xiao, Z., J.T. M cGrew, A.J. Schroeder, and M. Fitzgerald-Hayes. 1993. CSE1 and CSE2, two new genes required for accurate mitotic chromosome segregation in Saccharomyces cerevisiae. Mol. Cell. Biol. 13: 4691-4702. 


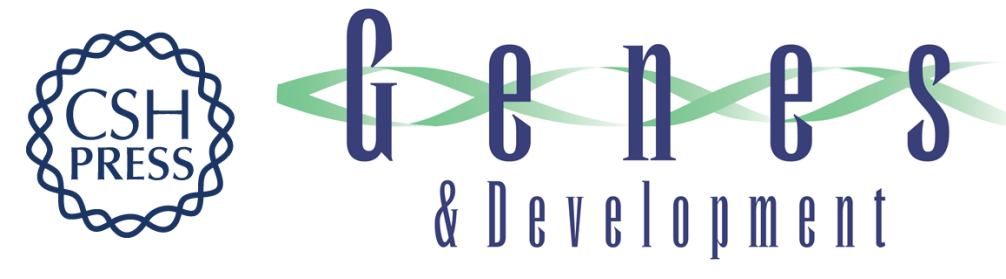

\section{Phosphorylation regulates association of the transcription factor Pho4 with its import receptor Pse1/Kap121}

Arie Kaffman, Nicole Miller Rank and Erin K. O'Shea

Genes Dev. 1998, 12:

Access the most recent version at doi:10.1101/gad.12.17.2673

References This article cites 61 articles, 29 of which can be accessed free at: http://genesdev.cshlp.org/content/12/17/2673.full.html\#ref-list-1

License

Email Alerting

Receive free email alerts when new articles cite this article - sign up in the box at the top Service right corner of the article or click here.

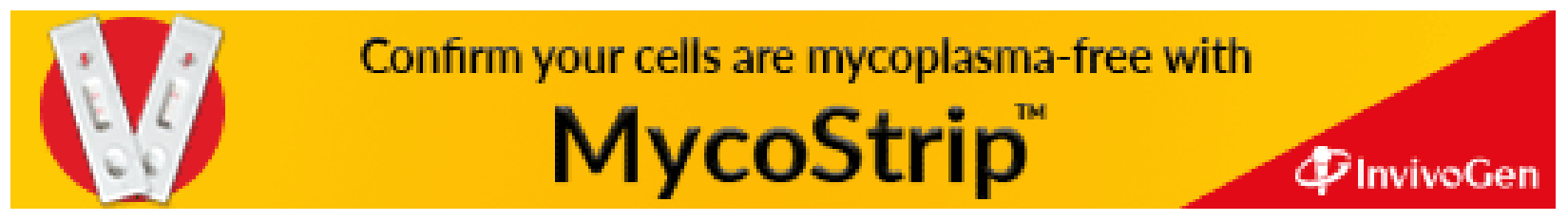

